\title{
The surprising negative correlation of gene length and optimal codon use - disentangling translational selection from GC-biased gene conversion in yeast
}

Nina Stoletzki ${ }^{1,2,3}$

\begin{abstract}
Background: Surprisingly, in several multi-cellular eukaryotes optimal codon use correlates negatively with gene length. This contrasts with the expectation under selection for translational accuracy. While suggested explanations focus on variation in strength and efficiency of translational selection, it has rarely been noticed that the negative correlation is reported only in organisms whose optimal codons are biased towards codons that end with G or C (-GC). This raises the question whether forces that affect base composition - such as GC-biased gene conversion contribute to the negative correlation between optimal codon use and gene length.

Results: Yeast is a good organism to study this as equal numbers of optimal codons end in -GC and -AT and one may hence compare frequencies of optimal GC- with optimal AT-ending codons to disentangle the forces. Results of this study demonstrate in yeast frequencies of GC-ending (optimal AND non-optimal) codons decrease with gene length and increase with recombination. A decrease of GC-ending codons along genes contributes to the negative correlation with gene length. Correlations with recombination and gene expression differentiate between GC-ending and optimal codons, and also substitution patterns support effects of GC-biased gene conversion.

Conclusion: While the general effect of GC-biased gene conversion is well known, the negative correlation of optimal codon use with gene length has not been considered in this context before. Initiation of gene conversion events in promoter regions and the presence of a gene conversion gradient most likely explain the observed decrease of GC-ending codons with gene length and gene position.
\end{abstract}

Keywords: GC-biased gene conversion optimal codon use, cause of correlation

\section{Background}

Translational selection on synonymous codon use is indicated if frequencies of preferentially used, 'optimal', codons increase with expression level and correspond to the most abundant tRNA or to the tRNA with which they form the strongest binding - for several organisms, this seems to be the case (see for reviews [1-4]). Additional support for a beneficial role of certain 'optimal' codons in translation comes from laboratory studies [5-8]. Translational selection may act to maximise the

\footnotetext{
Correspondence: NStoletzki@googlemail.com

'Ludwig-Maximilan Universität, Biocenter, Grosshadernerstr. 2, D-82152

Planegg-Martinsried, Germany

Full list of author information is available at the end of the article
}

speed of elongation, minimize the costs of proofreading or maximise the accuracy of translation [1], and depending on the selective target, one can test further distinct predictions. Under selection for translational accuracy we expect for example: (i) selection against translational errors to relate to the error's costs. As costs of an erroneous protein should accrue with each added amino acid during protein synthesis, one may expect long genes to experience higher optimal codon use than short genes [9]. Supporting selection for translational accuracy, in E. coli and yeast, relative optimal codon use indeed increases with gene length [9-12]. (ii) We also expect selection against translational errors to relate to the error's functional effect: translational errors for
C Biomed Central

(c) 2011 Stoletzki; licensee BioMed Central Ltd. This is an Open Access article distributed under the terms of the Creative Commons Attribution License (http://creativecommons.org/licenses/by/2.0), which permits unrestricted use, distribution, and reproduction in any medium, provided the original work is properly cited. 
some amino acids may have no functional effects, while for other amino acids, translational errors render a protein non-functional. The latter should be under stronger selection for translational accuracy. As Akashi [13] points out, the functional importance of amino acid site may be approximated by its evolutionary conservation. Under translational selection for accuracy one may hence expect higher optimal codon frequencies at conserved than at non-conserved amino acid sites. This is indeed the case in D. melanogaster, C. elegans, E. coli [12-14]; a recent study [15] indicates this pattern may also apply to mouse and human using a modified measure of optimal codons.

However, surprisingly, in D. melanogaster, C. elegans, A. thaliana, and humans, optimal codon use decreases with gene length, thereby opposing the prediction under selection for translational accuracy [16-18]. This decrease is particularly surprising for species, in which selection for translational accuracy is indicated by the aforementioned higher optimal codon use at conserved amino acid sites. The explanation may be that the negative correlation between optimal codon use and gene length simply is a side effect: highly expressed genes with high optimal codon use tend to be short, possibly to be more economic [19]. Yet, while control of expression level affects the correlation of optimal codon use with gene length in yeast, causing a change from negative to positive $[10,11]$, in D. melanogaster, C. elegans, A. thaliana or humans, the negative correlation of optimal codon use with gene length does not seem to be due to a correlation of gene length with expression level only $[11,17,18,20,21]$.

Two explanations for the negative correlation have been proposed, both of which are based on translational selection. First, under selection for translational efficiency, selection for optimal codons may decrease with gene length due to the decrease in the relative fitness effect per optimal codon [16]. The second hypothesis invokes Hill-Robertson interference [22], which considers the reduction in selective efficacy due to linkage among sites: weakly or strongly selected sites that evolve adaptively or under constraints may affect evolutionary dynamics of linked sites. As Comeron et al. [16] suggest selection efficacy on optimal codons may decrease with gene length, as long genes with higher numbers of potentially interfering sites may experience a stronger Hill-Robertson effect. The Hill-Robertson effect has been considered for various effects on synonymous codons [e.g. [23-29]]. As recombination breaks down linkage, the observed positive correlation of optimal codon use with recombination rate was taken as support for the HillRobertson effect reducing the efficacy of translational selection on optimal codons [30-32].
Yet, optimal codons in several metazoans, such as the ones for which the negative correlation was first reported for, i.e. D. melanogaster, C. elegans and A. thaliana, but also for humans are mostly ending with $\mathrm{G}$ or $\mathrm{C}(-\mathrm{GC})$ [see codon tables in $[17,18]$ ], and compositionally biased mutation or repair processes may indirectly affect optimal codon use. Recombination-dependent repair (gene conversion) is indeed biased towards -GC in many organisms including yeast, mice, humans and Drosophila [20,33-36], and hence may be the potential force. Effects of GC-biased gene conversion will be most obvious at sites that evolve neutrally or under weak selection, and the substitution patterns it leaves resembles that of directional selection [see for review [36]]. GC-biased gene conversion has been indicated to affect optimal codon use before: optimal codon frequencies increase with recombination rate, a patterns consistent with population genetic predictions under translational selection on optimal codons [30,31]. However, in D. melanogaster and C. elegans not only optimal codon frequencies increase with recombination, but also non-optimal ones, as long as they end with -GC [20,37]. The positive correlation of non-optimal GC-ending codon frequencies with recombination indicates the observed positive correlation optimal (GCending) codons - that was taken as evidence for reduced efficacy of translational selection due to Hill-Robertson interference - is likely affected by compositionally biased processes such GC-biased gene conversion [20,37]. Whether or not GC-biased gene conversion or HillRobertson effects the positive correlation between optimal codons and recombination attracted controversy [see for example [20,37] versus [31,32]], but with respect to the observed negative correlation of optimal codon use with gene length, GC-biased gene conversion has never been considered.

The negative correlation of optimal codon use with gene length is found in organisms whose optimal codons are biased towards GC-ending ones, and may hence be caused by forces acting on optimal codons or on base composition. As translational selection affects optimal codons, while a compositional bias like gene conversion affects GC-ending codons, one may disentangle the effects by looking at optimal and non-optimal GC- and AT-ending codons separately. Saccharomyces cerevisiae is a good organism to disentangle the two forces because translationally optimal codons are not biased towards GC-ending ones as in the above mentionned organisms. Furthermore, translational selection and GC-biased gene conversion are comparably wellstudied and supported in S. cerevisiae [e.g. [34,38,39]].

Results of this study demonstrate in $S$. cerevisiae the frequency of GC-ending (optimal AND non-optimal) codons decreases with gene length and increases with 
recombination. Also a decrease of GC-ending codons along genes is indicated. This distinction between AT- and GC-ending codons cannot be explained by variation in strength and efficiency of translational selection, while GC-biased gene conversion may explain the observation. Substitutions at four-fold degenerated sites differ between AT-> GC and GC->AT changes, further supporting an effect of GC-biased gene conversion. Initiation of gene conversion events in promoter regions and the presence of a gene conversion gradient most likely explain the observed decrease of GC-ending codons with gene length and gene position.

\section{Results}

\section{Difference between optimal codons depending on} whether they end with -AT or -GC

To disentangle forces affecting base compositions (such as GC-biased gene conversion) from translational selection on optimal codons, one can compare optimal GC-ending and optimal AT-ending codons. As expected under translational selection, all optimal codons independent of their third nucleotide increase with gene expression (Table 1). As expected under GC-biased gene conversion, only the frequency of GC-ending optimal codons increases with recombination, AT-ending optimal codons however tend to be negatively or not significantly correlated with recombination (Table 1). Crucially with respect to gene length, only the relative frequencies of AT-ending optimal codons increase with gene length as one may expect under selection for translational accuracy. In contrast, the relative frequencies of GC-ending optimal codons decrease with gene length. This is true for individual amino acids, as well as for groups of amino acids with either AT-or with GCending optimal codons $\left(\mathrm{F}_{\mathrm{OP}} \mathrm{AT}\right.$, and $\mathrm{F}_{\mathrm{OP}} \mathrm{GC}$ respectively; Table 1). This distinction between optimal AT- and optimal GC-ending codons indicates an effect related to base composition.

Interrelated variables such as expression level may affect correlations between codon use and gene length. To control for all possible interrelated variables, and especially for noisy variables such as expression level is not easy $[40,41]$. However, as the same genes were used for comparing AT- and GC-ending optimal codons, a control of other variables is not necessary to highlight their difference. AT- and GC-ending optimal codons are sampled from the same distributions of other potentially affecting variables such as expression level. The effect of gene expression (and other variables) should hence affect them both similarly. The major difference between ATand GC-ending optimal codons can hence be demonstrated by simple Spearman rank correlation analyses: expression level should affect all (AT- and GC-ending) optimal codons similarly, while clearly, GC-ending codons differ from AT-ending codons in their correlation
Table 1 Difference of optimal codons depending on whether they end with -GC or -AT

\begin{tabular}{|c|c|c|c|}
\hline Amino acid & $\begin{array}{l}\text { Gene } \\
\text { length }\end{array}$ & Expression & Recombination \\
\hline \multicolumn{4}{|c|}{$\mathrm{F}_{\mathrm{OP}} \mathrm{AT}$ : $\mathrm{F}_{\mathrm{OP}}$ for aminoacids with AT-ending optimal codons } \\
\hline $\begin{array}{l}\text { Ala } \\
\mathrm{N}=53719 \text { codons }\end{array}$ & $+0.0229 \mathrm{NS}$ & $+0.2546^{* * *}$ & $\begin{array}{l}\text { Co:-0.0656** } \\
\text { nCo:-0.0217NS } \\
\text { spo11:-0.0856*** } \\
\text { dmc1:-0.0540* } \\
\text { mre11 } 1 \text { : }+0.0147 \mathrm{NS} \\
\text { mre11 } 16:-0.0659^{* *}\end{array}$ \\
\hline $\begin{array}{l}\text { Arg } \\
\mathrm{N}=43139 \text { codons }\end{array}$ & $+0.0002 \mathrm{NS}$ & $+0.4301^{* * *}$ & $\begin{array}{l}\text { Co:+0.0293NS } \\
\text { nCo:+0.0265NS } \\
\text { spo 11:+0.0297NS } \\
\text { dmc1:+0.0488NS } \\
\text { mre1 } 10:+0.0375 \mathrm{NS} \\
\text { mre11 } 1:-0.0037 \mathrm{NS}\end{array}$ \\
\hline $\begin{array}{l}\text { Cys } \\
\mathrm{N}=13614 \text { codons }\end{array}$ & $+0.0535^{*}$ & $+0.2293^{* * *}$ & $\begin{array}{l}\text { Co:-0.0162NS } \\
\text { nCo:-0.0239NS } \\
\text { spo11:-0.0229NS } \\
\text { dmc1:+0.0030NS } \\
\text { mre1 } 10:+0.0172 \mathrm{NS} \\
\text { mre11 } 16:-0.0158 \mathrm{NS}\end{array}$ \\
\hline $\begin{array}{l}\text { Gln } \\
N=38581 \text { codons }\end{array}$ & $+0.0603^{*}$ & $+0.2076^{* * *}$ & $\begin{array}{l}\text { Co:-0.0777** } \\
\text { nCo:-0.0546* } \\
\text { spo11:-0.0495NS } \\
\text { dmc1:-0.0873*** } \\
\text { mre11 }:=0.0532 \mathrm{NS} \\
\text { mre116:-0.0565* }\end{array}$ \\
\hline $\begin{array}{l}\text { Glu } \\
N=65707 \text { codons }\end{array}$ & $+0.1396^{* * *}$ & $+0.1663^{* * *}$ & $\begin{array}{l}\text { Co:-0.0658** } \\
\text { nCo:-0.0573* } \\
\text { spo11:-0.0796** } \\
\text { dmc1:-0.1154*** } \\
\text { mre1 1 } 0:-0.0252 \mathrm{NS} \\
\text { mre11 } 16:-0.0822^{* *}\end{array}$ \\
\hline $\begin{array}{l}\text { Gly } \\
\mathrm{N}=49861 \text { codons }\end{array}$ & $+0.0470 \mathrm{NS}$ & $+0.4385^{* * *}$ & $\begin{array}{l}\text { Co: }+0.0241 \mathrm{~S} \\
\text { nCo:+0.0230NS } \\
\text { spo11:+0.0298NS } \\
\text { dmc1:+0.0406NS } \\
\text { mre1 } 11_{0}:+0.0831^{* *} \\
\text { mre11 } 1:-0.0037 \mathrm{NS}\end{array}$ \\
\hline $\begin{array}{l}\text { Pro } \\
\mathrm{N}=43069 \text { codons }\end{array}$ & $+0.0304 \mathrm{NS}$ & $+0.3114^{* * *}$ & $\begin{array}{l}\text { Co:-0.0509* } \\
\text { nCo:-0.0292NS } \\
\text { spo11:+0.0105NS } \\
\text { dmc1:-0.0481NS } \\
\text { mre1 } 10:+0.0116 \mathrm{NS} \\
\text { mre11 } 16:-0.0348 \mathrm{NS}\end{array}$ \\
\hline $\begin{array}{l}\text { Grouped } \\
N=307690 \text { codons } \\
R^{2}=0.300^{* * *} \\
P(G L)^{* * *}, P(\text { Expr) } \\
P(\text { dmc1 })^{* * * *}\end{array}$ & $+0.1271^{* * *}$ & $+0.3732^{* * *}$ & $\begin{array}{l}\text { Co:-0.0867** } \\
\text { mCo:-0.0556* } \\
\text { spo11:-0.0086*** } \\
\text { dmc1:-0.1643*** } \\
\text { mre110:-0.0601* } \\
\text { mre11 } 6:-0.1074^{* * *}\end{array}$ \\
\hline \multicolumn{4}{|c|}{ FoP $_{\mathrm{OP}} \mathrm{G}$. $\mathrm{OP}_{\mathrm{P}}$ for aminoacids with GC-ending optimal codons } \\
\hline $\begin{array}{l}\text { Leu } \\
N=96687 \text { codons }\end{array}$ & $-0.1031^{* * *}$ & $+0.3690^{* * *}$ & $\begin{array}{l}\text { Co: }+0.1828^{* * *} \\
\text { nCo:+0.1451*** } \\
\text { spo11:+0.2015*** } \\
\text { dmc1:+0.2526*** } \\
\text { mre1 1 } 1:+0.1206^{* * *} \\
\text { mre11 } 6_{6}:+0.1344^{* * *}\end{array}$ \\
\hline $\begin{array}{l}\text { Asn } \\
N=60930 \text { codons }\end{array}$ & $-0.1588^{* * *}$ & $+0.2880^{* * *}$ & 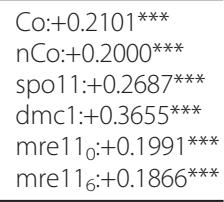 \\
\hline
\end{tabular}


Table 1 Difference of optimal codons depending on whether they end with -GC or -AT (Continued)

\begin{tabular}{|c|c|c|c|}
\hline $\begin{array}{l}\text { Asp } \\
N=60058 \text { codons }\end{array}$ & $-0.1995^{* * *}$ & $+0.1485^{* * *}$ & $\begin{array}{l}\text { Co:+0.1976*** } \\
\text { nCo: }+0.1500^{* * *} \\
\text { spo11:+0.2602 } \\
\text { dmc1: } 10.3561^{* * *} \\
\text { mre11 } 10:+0.1437^{* * *} \\
\text { mre11 } 6^{*}:+0.1997^{* * *}\end{array}$ \\
\hline
\end{tabular}

\begin{tabular}{llll}
\hline Tyr & $-0.1850^{* * *}$ & $+0.2240^{* * *}$ & Co: $+0.1718^{* * *}$ \\
$\mathrm{~N}=32887$ codons & & & $\mathrm{nCo}+0.1401^{* * *}$
\end{tabular}
spo 11: $+0.2499^{* * *}$ dmc1: $+0.3186^{* * *}$ mre1 $10:+0.1834^{* * *}$ mre1 $16:+0.1704^{* * *}$

\begin{tabular}{llll}
\hline Phe & $-0.1103^{* * *}+0.2729^{* * *}$ & Co: $+0.2689^{* * *}$ \\
& &
\end{tabular}
$\mathrm{N}=44129$ codons $\quad \mathrm{nCo}:+0.1612^{* * *}$ spo 11:+0.2628*** dmc1: $+0.3413^{* * *}$ mre11 $10:+0.1933^{* * *}$ mre11 $6:+0.1772^{* * *}$

\begin{tabular}{llll}
\hline Lys & $-0.2207^{* * *}$ & $+0.3210^{* * *}$ & Co: $+0.2248^{* * *}$
\end{tabular}

$\mathrm{N}=72564$ codons $\quad \mathrm{nCo}:+0.1475^{* * *}$ spo11: $+0.2843^{* * *}$ dmc1: $+0.3632^{* * *}$ mre11 $:+0.1471^{* * *}$ mre11 $6:+0.2043^{* * *}$

\begin{tabular}{|c|c|c|c|}
\hline $\begin{array}{l}\text { His } \\
\mathrm{N}=21966 \text { codons }\end{array}$ & $-0.1010^{* * *}$ & $+0.1060^{* * *}$ & $\begin{array}{l}\text { Co: }: 0.1193^{* * *} \\
\text { nCo: }+0.1132^{* * *} \\
\text { spo } 11:+0.1623^{* * *} \\
\text { dmc1: }+0.2096^{* * *} \\
\text { mre11: }:+0.1086^{* * *} \\
\text { mre11 }:: 0.1357^{* * *}\end{array}$ \\
\hline $\begin{array}{l}\text { Grouped } \\
N=389221 \text { codons } R^{2}= \\
0.424, \\
P(G L)^{* * *}, P(\text { Expr })^{* * *} \\
P\left(d m c 1, \text { mre } 11_{0}\right)^{* * *}\end{array}$ & $-0.2604^{* * *}$ & $+0.4005^{* * *}$ & 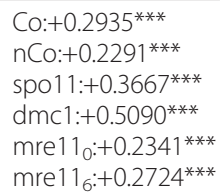 \\
\hline
\end{tabular}

Spearman Rank Correlations between optimal codon use, gene length, expression, and various recombination measures for amino acids and groups of amino acids with either AT- or with GC-ending optimal codons. 1554 genes for which all amino acids were present at least four times were used. Presented for grouped variables are also MR results of variables whose logtransformation did not grossly deviate from a normal distribution. ${ }^{*} \mathrm{P}<0.05$, ${ }^{*} \mathrm{P}<0.01,{ }^{* * *} \mathrm{P}<0.001, \mathrm{NS}=$ not significant.

with gene length and with recombination (Table 1). The opposing correlation of AT- and GC-ending optimal codons with gene length and recombination indicates another force unrelated to translational selection is acting.

Multiple regression (MR) analysis between log-transformed $\mathrm{F}_{\mathrm{OP}} \mathrm{GC}$ or $\mathrm{F}_{\mathrm{OP}} \mathrm{AT}$ estimates, gene length, expression and two different measures of recombination confirms independent effects of expression, recombination and gene length (Table 1). Please be aware however that both, recombination and expression measures will be noisy and as Plotkin and Fraser [40] highlight, one should not compare the explanatory power of predictors with standard regression techniques when the predictors contain different amounts of measurement noise.

\section{Effect of base composition independent of translational} selection

For amino acids with at least two optimal or with at least two non-optimal codons, one can estimate the relative GC-content of either optimal or at non-optimal codons separately. For amino acids which have two optimal codons, I estimate the frequency of GCending optimal codons relative to all optimal codons $\left(\mathrm{F}_{\mathrm{GC}} \mathrm{Opt}\right)$; for amino acids which have at least two non-optimal codons, I estimate the frequency of GCending non-optimal codons relative to all non-optimal $\left(\mathrm{F}_{\mathrm{GC}} \mathrm{NonOpt}\right)$. To look at optimal and non-optimal codons separately controls for translational selection. The analysis supports an effect of base composition: relative frequencies of $\mathrm{GC}$-ending codons $\left(\mathrm{F}_{\mathrm{GC}} \mathrm{Opt}\right.$ and $\mathrm{F}_{\mathrm{GC}}$ Non-opt) consistently decrease with gene length and increase with recombination (Table 2). For all but Arg, the correlations are significant per amino acid; when grouped across respective amino acids, the decrease is significant for both $\mathrm{F}_{\mathrm{GC}} \mathrm{Opt}$ and $\mathrm{F}_{\mathrm{GC}}$ Nonopt (Table 2).

Notably, the analysis also indicates expression may affect the frequencies of GC-ending codons: controlling for translational selection, $\mathrm{GC}$-ending codons, $\mathrm{F}_{\mathrm{GC}} \mathrm{Opt}$ and $\mathrm{F}_{\mathrm{GC}}$ Non-opt, increase with expression level. This may be a side effect: first, in yeast, recombination and gene expression seem coupled [42] and secondly, highly expressed genes tend to be short [19]. However, it may also reveal some selective force: GC-ending codons affect for example thermodynamic stability and hence mRNA secondary structures which may be under selection [43-46] (see also Discussion). MR analysis between log-transformed variables supports independent effects of gene length, expression and recombination for the grouped data (Table 2).

\section{Effect of gene position on relative codon frequencies}

Intragenic variation in codon use exists: optimal codons may for example increase along genes due to selection against non-sense errors [9,12]; also a decrease of GCcontent along genes has been described $[29,47]$. To investigate an effect of gene position, I look at the four different measures of tables 1 and 2 for grouped amino acids:

$\mathrm{F}_{\mathrm{OP}} \mathrm{GC}=$ frequency of optimal codons relative to all synonymous codons, but only for amino acids which have optimal codons that end with $\mathrm{G}$ or $\mathrm{C}$;

$\mathrm{F}_{\mathrm{OP}} \mathrm{AT}=$ frequency of optimal codons relative to all synonymous codons, but only for amino acids which have optimal codons that end with $\mathrm{A}$ or $\mathrm{T}$;

$\mathrm{F}_{\mathrm{GC}} \mathrm{Opt}=$ frequency of $\mathrm{GC}$-ending optimal codons relative to all optimal codons; only for amino acids which have two optimal codons, one ending with $G$ or $\mathrm{C}$ the other with $\mathrm{A}$ or $\mathrm{T}$; 
$\mathrm{F}_{\mathrm{GC}} \mathrm{Non}$-opt $=$ frequency of GC-ending non-optimal codons relative to all non-optimal; only for amino acids which have at least two non-optimal codons, one ending with $\mathrm{G}$ or $\mathrm{C}$ and one with $\mathrm{A}$ or $\mathrm{T}$.

Results show that optimal codons $\left(\mathrm{F}_{\mathrm{OP}} \mathrm{GC}\right.$ and $\mathrm{F}_{\mathrm{OP}} \mathrm{AT}$ ) tend to increase with gene position, and GCending ones $\left(\mathrm{F}_{\mathrm{GC}} \mathrm{Opt}\right.$ and $\mathrm{F}_{\mathrm{GC}}$ Non-opt) tend to decrease (Table 3). The result remains excluding the first 50 codons that often appear to be under different pressures $[29,48]$. The non-significant result for $\mathrm{F}_{\mathrm{OP}} \mathrm{GC}$ may be due to conflicting pressures: optimal codons tend to increase while GC-ending codons tend to decrease. The non-significant result of $\mathrm{F}_{\mathrm{GC}} \mathrm{Opt}$ may be due to dominant selection on optimal codons that is stronger than additional compositional forces.

An increase (or decrease) of certain codons along genes will as a side effect cause a positive (or negative) correlation of these codons with gene length [12]. To control for this effect of gene position, I take genes that are greater than 300 codons and only consider the level of bias in those codons from number 50 up to codon number 300 [12]. I repeat the two previous analyses (Tables 1 and 2) for the grouped data. The general patterns that GC-ending codons tend to decrease with gene length and increase with recombination remains, but becomes non-significant for the correlation between $\mathrm{F}_{\mathrm{GC}}$ Non-opt and gene length (Table 4). The positive correlation between $\mathrm{F}_{\mathrm{OP}} \mathrm{AT}$ and gene length disappears indicating selection for translational accuracy may mainly act against non-sense errors [see [12]]. The two measures that showed no significant effect of gene position, $\mathrm{F}_{\mathrm{OP}} \mathrm{GC}$ and $\mathrm{F}_{\mathrm{GC}} \mathrm{Opt}$ (Table 3 ) remain significantly negative correlated after the control of gene position (Table 4). MR analysis of log-transformed variables indicates no independent effect of gene length for any codon class after controlling for position (Table 4). The results hence support that GC-ending codons tend to decrease along genes, and that this decrease along genes contributes considerably to the negative correlation of GC-ending codons with gene length.

\section{Substitution rates and patterns}

For both, GC-biased gene conversion as well as translational selection, we may not only expect relative codon frequencies to mirror the respective forces, but also substitution patterns. To disentangle the effect of gene conversion from translational selection, I take four-fold degenerated changes that do not change the non-optimal codon status and estimate four rates of substitutions AT $->\mathrm{GC}, \mathrm{GC}->\mathrm{AT}, \mathrm{AT}->\mathrm{AT}$, and GC->GC. Under GC-biased gene conversion, we expect an increase of
Table 2 Effect of base composition independent of translational selection

\begin{tabular}{|c|c|c|c|}
\hline Amino acid & $\begin{array}{l}\text { Gene } \\
\text { length }\end{array}$ & Expression & Recombination \\
\hline \multicolumn{4}{|c|}{$\mathrm{F}_{\mathrm{GC}} \mathrm{opt}$ : Frequency of GC-ending optimal codons, $\mathrm{n}=1506$ genes } \\
\hline $\begin{array}{l}\text { Ile } \\
N=47505 \text { codons }\end{array}$ & $-0.1567^{* * *}$ & $+0.1026^{* * *}$ & $\begin{array}{l}\text { Co: }+0.2280^{* * *} \\
\text { nCo: }+0.2027^{* * *} \\
\text { spo11: }+0.2754^{* * *} \\
\text { dmc1:+0.3490***} \\
\text { mre1 } 11_{0}:+0.1663^{* * *} \\
\text { mre1 } 16:+0.2185^{* * *}\end{array}$ \\
\hline $\begin{array}{l}\text { Ser } \\
N=36478 \text { codons }\end{array}$ & $-0.1054^{* * *}$ & $+0.0354 \mathrm{NS}$ & 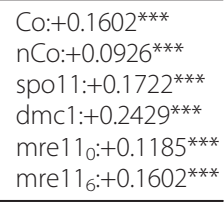 \\
\hline $\begin{array}{l}\text { Thr } \\
N=30830 \text { codons }\end{array}$ & $-0.0899 * *$ & $+0.0837^{* *}$ & $\begin{array}{l}\text { Co: }=0.2019^{* * *} \\
\text { nCo: }+0.1365^{* * *} \\
\text { spo11: }+0.2252^{* * *} \\
\text { dmc1:+0.2827*** } \\
\text { mre1 } 10:+0.0958^{* *} \\
\text { mre11 } 6:+0.1302^{* * *}\end{array}$ \\
\hline $\begin{array}{l}\text { Val } \\
N=32710 \text { codons }\end{array}$ & $-0.1544^{* * *}$ & $+0.0954^{* * *}$ & 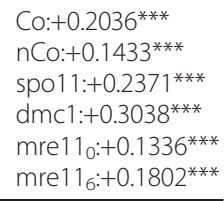 \\
\hline $\begin{array}{l}\text { Grouped } \\
N=261651 \text { codons } \\
R^{2}=0.194^{* * *} \\
P(G L)^{* * *}, P(\text { Expr })^{* *} P \\
(d m c 1, \\
\text { mre110) }\end{array}$ & $-0.2153^{* * *}$ & $+0.1304^{* * *}$ & 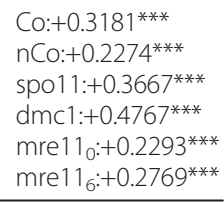 \\
\hline
\end{tabular}

$\mathrm{F}_{\mathrm{GC}}$ non-opt: Frequency of GC-ending non-optimal codons, $\mathrm{n}=$ 1276 genes

\begin{tabular}{|c|c|c|c|}
\hline $\begin{array}{l}\text { Ala } \\
N=30071 \text { codons }\end{array}$ & $-0.0855^{* *}$ & $+0.1573^{* * *}$ & $\begin{array}{l}\text { Co: }+0.1592^{* * *} \\
\text { nCo: }+0.1124^{* * *} \\
\text { spo 11:+0.2234 } \\
\text { dmc1: } 1: 0.2520^{* * * *} \\
\text { mre1 } 10:+0.1173^{* * *} \\
\text { mre11 } 6:+0.1586^{* * *}\end{array}$ \\
\hline $\begin{array}{l}\text { Arg } \\
N=15296 \text { codons }\end{array}$ & $-0.0152 \mathrm{NS}$ & $+0.2595^{* * *}$ & $\begin{array}{l}\text { Co:+0.0435NS } \\
\text { nCo: }+0.0651^{*} \\
\text { spo 11:+0.1235 } \\
\text { dmc1: } 1: 0.1255^{* * * *} \\
\text { mre1 } 10:+0.0714^{*} \\
\text { mre1 } 16:+0.0893^{* *}\end{array}$ \\
\hline $\begin{array}{l}\text { Gly } \\
N=23663 \text { codons }\end{array}$ & $-0.0689^{*}$ & $+0.1643^{* * *}$ & $\begin{array}{l}\text { Co: }+0.1707^{* * *} \\
\text { nCo: }: 0.1559^{* * *} \\
\text { spo 11:+0.2027 } \\
\text { dmc1: } 10.2850^{* * *} \\
\text { mre1 } 10:+0.1697^{* * *} \\
\text { mre11 } 6:+0.1397^{* * *}\end{array}$ \\
\hline $\begin{array}{l}\text { Leu } \\
N=62345 \text { codons }\end{array}$ & $-0.1961^{* * *}$ & $-0.0819^{* *}$ & $\begin{array}{l}\text { Co: }+0.2238^{* * *} \\
\text { nCo: }+0.1806^{* * *} \\
\text { spo 11:+0.2578 } \\
\text { dmc1: } 1+0.3524^{* * *} \\
\text { mre1 1 } 0:+0.1106^{* * *} \\
\text { mre1 } 16:+0.1979^{* * *}\end{array}$ \\
\hline
\end{tabular}


Table 2 Effect of base composition independent of translational selection (Continued)

\begin{tabular}{|c|c|c|c|}
\hline $\begin{array}{l}\text { Pro } \\
N=23167 \text { codons }\end{array}$ & $-0.1141^{* * *}$ & $-0.1121^{* * *}$ & $\begin{array}{l}\text { Co: }+0.1576^{* * *} \\
\text { nCo:+0.1333*** } \\
\text { spo 11:+0.1384*** } \\
\text { dmc1: }+0.2066^{* * *} \\
\text { mre1 1 } 0:+0.0792^{* *} \\
\text { mre11 } 6:+0.1310^{* * *}\end{array}$ \\
\hline $\begin{array}{l}\text { Thr } \\
N=22921 \text { codons }\end{array}$ & $-0.0736^{* *}$ & $-0.0469 \mathrm{NS}$ & $\begin{array}{l}\text { Co: }+0.1404^{* * *} \\
\text { nCo: }+0.1070^{* * *} \\
\text { spo11:+0.1571 } \\
\text { dmc1: } 1+0.1914^{* * * *} \\
\text { mre1 1 } 0:+0.0906^{* *} \\
\text { mre11 } 6:+0.0981^{* * *} \\
\end{array}$ \\
\hline $\begin{array}{l}\text { Ser } \\
N=45898 \text { codons }\end{array}$ & $-0.1153^{* * *}$ & $-0.0056 \mathrm{NS}$ & $\begin{array}{l}\text { Co: }+0.1943^{* * *} \\
\text { nCo: }+0.1194^{* * *} \\
\text { spo11:+0.2200*** } \\
\text { dmc1: }+0.2990^{* * *} \\
\text { mre11 } 0:+0.1669^{* * *} \\
\text { mre11 } 1_{0}:+0.1775^{* * *} \\
\end{array}$ \\
\hline $\begin{array}{l}\text { Val } \\
N=20558 \text { codons }\end{array}$ & $-0.0599 *$ & $+0.1127^{* * *}$ & $\begin{array}{l}\text { Co: }+0.2433^{* * *} \\
\text { nCo: }+0.1623^{* * *} \\
\text { spo 11:+0.1956*** } \\
\text { dmc1: }+0.2672^{* * *} \\
\text { mre1 10:+0.1468*** } \\
\text { mre11 } 6:+0.1747^{* * *}\end{array}$ \\
\hline $\begin{array}{l}\text { Grouped } \\
N=341847 \text { codons } \\
R^{2}=0.727^{* * *} \\
P(G L)^{* * *}, P(\text { Expr })^{* * *} \\
P(d m c 1)^{* * *}, \\
P(\text { mre110) NS }\end{array}$ & $-0.2858^{* * *}$ & $+0.0820^{* *}$ & $\begin{array}{l}\text { Co:+0.3194*** } \\
\text { nCo: }+0.2443^{* * *} \\
\text { spo 11:+0.3526 } \\
\text { dmc1:+ } 0.5357^{* * * *} \\
\text { mre11 } 0:+ \\
0.2620^{* * *} \\
\text { mre11 } 6^{*}+0.2978^{* * *}\end{array}$ \\
\hline
\end{tabular}

Spearman Rank Correlations between the frequency of GC-ending optimal or non-optimal codons with gene length, expression, and various recombination measures. For each amino acid, only genes were used for which at least 4 optimal or 4 non-optimal codons were present respectively. Presented for grouped variables are also MR results of variables whose log-transformation did not grossly deviate from a normal distribution. ${ }^{*} \mathrm{P}<0.05$, ${ }^{* * P}<0.01$, ${ }^{* * * P}<$ $0.001, \mathrm{NS}=$ not significant.

AT-> GC (and a decrease of GC->AT) with recombination. As for the relative frequencies, the same genes are used for comparison, so a control of other variables should not be necessary to highlight their differences. However, while differences with respect to recombination can indeed be observed, a general decrease of all substitution rates with gene expression (and increase with gene length) confounds the observation (Table 5). Higher expressed (and shorter) genes appear more constraint even at non-optimal sites and indicate again beneficial roles of non-optimal codons for gene expression.

To look at the proportion of the rates of $\mathrm{AT}->\mathrm{GC}$ substitutions from all AT $<->\mathrm{GC}$ substitutions will control for this general increase in substitution rates. According to Sueoka [49], one may estimate the equilibrium of GC content, $\mathrm{GC}^{*}$, to which a sequence is evolving to by $\mathrm{GC}^{*}=\mathrm{u} /(\mathrm{u}+\mathrm{v})$, with $\mathrm{u}=$ rate $\mathrm{AT}->\mathrm{GC}$, and $\mathrm{v}$ $=$ rate $\mathrm{GC}->\mathrm{AT}$. Sueoka's model assumes that all sites within a sequence evolve independently and as $\mathrm{CpG}$ do not appear hyper-mutable in yeast [50] one may use this
Table 3 Effect of gene position

\begin{tabular}{|c|c|}
\hline & Position 1-300 (49-300) \\
\hline $\begin{array}{l}\text { F }_{\text {OPAT }} \\
\mathrm{N}=27933 \text { codons }\end{array}$ & $+0.2679^{* * *}\left(+0.2656^{* * *}\right)$ \\
\hline $\begin{array}{l}\mathrm{F}_{\mathrm{OP}} \mathrm{GC} \\
\mathrm{N}=33897 \text { codons }\end{array}$ & $+0.1244^{*}(+0.0648 \mathrm{NS})$ \\
\hline $\begin{array}{l}\mathbf{F}_{\mathbf{G C}} \mathbf{O p t} \\
\mathrm{N}=19794 \text { codons }\end{array}$ & $-0.0647 N S(-0.1091 N S)$ \\
\hline $\begin{array}{l}\text { F }_{\mathrm{GC}} \text { Non-opt } \\
\mathrm{N}=24446 \text { codons }\end{array}$ & $-0.1227^{*}\left(-0.1591^{* *}\right)$ \\
\hline
\end{tabular}

simple approach. To control for translational selection, I again only consider four-fold degenerate changes that do not change the non-optimal codon status and estimate the proportion of AT->GC. This confirms an increase of the proportion of AT->GC substitutions with recombination as expected under GC-biased gene conversion and a decrease with gene length (Table 5). The proportion AT-> GC further slightly increases with

\section{Table 4 Controlling the effect of gene position}

\begin{tabular}{|c|c|c|c|}
\hline & $\begin{array}{l}\text { Gene } \\
\text { length }\end{array}$ & Expression & Recombination \\
\hline $\begin{array}{l}\mathbf{F}_{\text {OPAT }} \\
N=147193 \text { codons } \\
R^{2}=0.260^{* * *} \\
P(G L) N S, P(\text { Expr })^{* * *} \\
P(\text { dmcl, mre11 })^{* * *}\end{array}$ & $-0.0480 \mathrm{NS}$ & $+0.3696^{* * *}$ & $\begin{array}{l}\text { Co:-0.1064*** } \\
\text { nCo:-0.0922*** } \\
\text { spo11:-0.0442NS } \\
\text { dmc1:-0.1224*** } \\
\text { mre11 }:-0.0520^{*} \\
\text { mre116:- } \\
0.0922^{* * *}\end{array}$ \\
\hline $\begin{array}{l}\text { FoP }_{\text {OP }} \\
N=180789 \text { codons } \\
R^{2}=0.445^{* * *} \\
P(G L) N S, P(\text { Expr })^{* * *} \\
P(m r e 11)^{*} \\
P(\text { dmc } 1)^{* * *}\end{array}$ & $-0.1289^{* * *}$ & $+0.3839^{* * *}$ & $\begin{array}{l}\text { Co:+3284*** } \\
\text { nCo: }+0.2472^{* * *} \\
\text { spo 11:+0.3909*** } \\
\text { dmc1:+0.4829*** } \\
\text { mre11 } 0:+2648^{* * *} \\
\text { mre116: } \\
+0.2669^{* * *}\end{array}$ \\
\hline $\begin{array}{l}\mathrm{F}_{\mathrm{GC}} \text { Opt } \\
\mathrm{N}=70401 \text { codons } \\
\mathrm{R}^{2}=0.174^{* * *} \\
\mathrm{P}(\mathrm{GL}) \mathrm{NS}, \mathrm{P} \text { (Expr)NS P } \\
(\mathrm{dmc1}, \\
\left.\text { mre11 }_{0}\right)^{* * *}\end{array}$ & $-0.0751^{* *}$ & $+0.1216^{* * *}$ & $\begin{array}{l}\text { Co: }+0.2735^{* * *} \\
\text { nCo: }+0.1843^{* * *} \\
\text { spo } 11:+0.3232^{* * *} \\
\text { dmc1:+0.3837*** } \\
\text { mre11 } 0 \\
+0.2104^{* * *} \\
\text { mre11 } 1_{6}: \\
+0.2368^{* * *}\end{array}$ \\
\hline $\begin{array}{l}\text { F }_{\mathrm{GC}} \text { Non-Opt } \\
\mathrm{N}=126878 \text { codons } \\
\mathrm{R}^{2}=0.224^{* * *} \\
\mathrm{P}(\mathrm{GL}) \mathrm{NS}, \mathrm{P}(\text { Expr })^{* * *} \\
\mathrm{P}(\mathrm{dmc1} \\
\text { mre11 })^{* * *}\end{array}$ & $-0.0481 \mathrm{NS}$ & $+0.0410 \mathrm{NS}$ & $\begin{array}{l}\text { Co: }+0.2990^{* * *} \\
\text { nCo: }+0.2339^{* * *} \\
\text { spo 11: }+0.3506^{* * *} \\
\text { dmc1: }+0.4390^{* * *} \\
\text { mre110: } \\
+0.2311^{* * *} \\
\text { mre11 } 6^{\text {: }} \\
+0.2754^{* * *}\end{array}$ \\
\hline
\end{tabular}

Spearman Rank Correlations between frequencies of optimal and GC-ending codons with gene length, expression, and various recombination measures after controlling for a potential effect of gene position. The same 1571 genes were used for all measures. Presented are also MR results of variables whose log-transformation did not grossly deviate from a normal distribution. ${ }^{*} \mathrm{P}<$ $0.05,{ }^{* * P}<0.01,{ }^{* * * P}<0.001$ 
Table 5 Substitution patterns

\begin{tabular}{|c|c|c|c|}
\hline & $\begin{array}{l}\text { Gene } \\
\text { length }\end{array}$ & Expression & Recombination \\
\hline \multicolumn{4}{|l|}{2761 genes } \\
\hline $\begin{array}{l}\text { AT }->\text { GC } \\
n=47762 \text { conserved, } 7014 \\
\text { changes } \\
R^{2}=0.038^{* * *} \\
P(G L)^{* * *}, P(\text { Expr })^{* *} \\
P(\text { dmc1 })^{* * * *}, P\left(\text { mre } 11_{0}\right) N S\end{array}$ & $+0.1082^{*}$ & $-0.1922^{* * *}$ & $\begin{array}{l}\text { Co: }+0.0178 \mathrm{NS} \\
\text { nCo:+0.0041NS } \\
\text { spo11: } \\
+0.0218 \mathrm{NS} \\
\text { dmc1: } \\
+0.0290 \mathrm{NS} \\
\text { mre11: } \\
+0.0252 \mathrm{NS} \\
\text { mre11 } 6 \\
+0.0287 \mathrm{NS}\end{array}$ \\
\hline $\begin{array}{l}\text { GC }->\text { AT } \\
n=26739 \text { conserved, } 5677 \\
\text { changes } \\
R^{2}=0.068^{* * *} \\
P(G L)^{* * *}, P(\exp )^{* *} \\
P(d m c 1, \text { mre11 })^{* * *}\end{array}$ & $+0.2193^{* * *}$ & $-0.2435^{* * *}$ & $\begin{array}{l}\text { Co:-0.1277*** } \\
\text { nCo:-0.0338** } \\
\text { spo11:- } \\
0.1502^{* * *} \\
\text { dmc1:-0.1636*** } \\
\text { mre0:-0.1193*** } \\
\text { mre6:-0.1112*** }\end{array}$ \\
\hline $\begin{array}{l}\text { GC }->\text { GC } \\
n=26739 \text { conserved, } 842 \\
\text { changes } \\
R^{2}=0.349^{* * *} \\
P(G L)^{* * *}, P(\text { expr }) N S, \\
P(\text { dmc1 })^{* * *}, P(\text { mre11 } 1)^{* *}\end{array}$ & $+0.2048^{* * *}$ & $-0.1615^{* * *}$ & $\begin{array}{l}\text { Co:+0.0210NS } \\
\text { nCo: }+0.0343 \mathrm{NS} \\
\text { spo: }+0.0027 \mathrm{NS} \\
\text { dmc1:-0.0234NS } \\
\text { mre0:+0.0173NS } \\
\text { mre6:-0.0160NS } \\
\end{array}$ \\
\hline $\begin{array}{l}\text { AT }->\text { AT } \\
n=47762 \text { conserved, } 281 \\
\text { changes } \\
R^{2}=0.746^{* * *} \\
P(G L)^{* * *}, P(\text { expr })^{* * *} \\
P\left(d m c 1, \text { mre } 11_{0}\right) \text { NS }\end{array}$ & $+0.1559^{* * *}$ & $-0.0454 \mathrm{NS}$ & $\begin{array}{l}\text { Co:-0.0156NS } \\
\text { nCo:-0.0388* } \\
\text { spo:-0.0804** } \\
\text { dmc1:-0.0735*** } \\
\text { mre11 } 1:- \\
0.0208 \mathrm{NS} \\
\text { mre116:- } \\
\text { 0.0063NS }\end{array}$ \\
\hline AT->GC/(AT->GC+GC->AT) & $-0.0752^{* * *}$ & $+0.0441^{*}$ & $\begin{array}{l}\text { Co: }+0.0983^{* * *} \\
\text { nCo: }+0.0211 \text { NS } \\
\text { spo11: } \\
+0.1103^{* * *} \\
\text { dmc1: } \\
+0.1213^{* * *} \\
\text { mre11: } \\
+0.0947^{* * *} \\
\text { mre11 } 6: \\
+0.0946^{* * *}\end{array}$ \\
\hline \multicolumn{4}{|c|}{1965 genes; controlling for effects of gene position } \\
\hline $\begin{array}{l}\text { AT-> GC } \\
n=29013 \text { conserved, } 4126 \\
\text { changes } \\
R^{2}=0.011^{* *} \\
P(G L) N S, P(\text { expr)NS, } \\
P(\text { dmc1, mre11 })^{*}\end{array}$ & $-0.0281 \mathrm{NS}$ & $-0.1210^{* * *}$ & $\begin{array}{l}\text { Co:+0.0264NS } \\
\text { nCo:-0.0084NS } \\
\text { spo 11: } \\
\text { +0.0241NS } \\
\text { dmc1: } \\
+0.0418 \mathrm{NS} \\
\text { mre110: } \\
\text { +0.0077NS } \\
\text { mre116: } \\
+0.0416 \mathrm{NS}\end{array}$ \\
\hline $\begin{array}{l}\text { GC-> AT } \\
n=18164 \text { conserved, } 3594 \\
\text { changes } \\
R^{2}=0.055^{* * *} \\
P(G L) N S, P(\text { Expr })^{*} P(d m c 1 \\
\text { mre11 } 1)^{* * *}\end{array}$ & $+0.0118 \mathrm{NS}$ & $-0.1420^{* * *}$ & 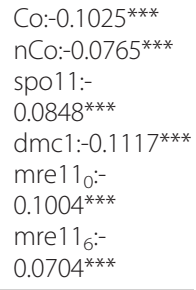 \\
\hline
\end{tabular}

Table 5 Substitution patterns (Continued)

\begin{tabular}{|c|c|c|c|}
\hline $\begin{array}{l}\text { GC-> GC } \\
n=18164 \text { conserved, } 509 \\
\text { changes }\end{array}$ & $-0.0136 \mathrm{NS}$ & $-0.0748^{* * *}$ & $\begin{array}{l}\text { Co:+0.0345NS } \\
\text { nCo:+0.0143NS } \\
\text { spo 11:+0.0556* } \\
\text { dmc1: } \\
+0.0433 \mathrm{NS} \\
\text { mre11 } 1_{0} \text { : } \\
+0.0038 \mathrm{NS} \\
\text { mre11 } 16 \text { : } \\
+0.0214 \mathrm{NS}\end{array}$ \\
\hline $\begin{array}{l}\text { AT-> AT } \\
n=29013 \text { conserved, } 171 \\
\text { changes }\end{array}$ & $-0.0460^{*}$ & $+0.0322 \mathrm{NS}$ & $\begin{array}{l}\text { Co:-0.0151NS } \\
\text { nCo:-0.0644** } \\
\text { spo:-0.0648* } \\
\text { dmc1:-0.0377NS } \\
\text { mre1 } 11_{0}: \\
+0.0031 \mathrm{NS} \\
\text { mre116: } \\
\text { +0.0285NS }\end{array}$ \\
\hline AT->GC/(AT->GC+GC->AT) & $-0.0329 \mathrm{NS}$ & $+0.0131 \mathrm{NS}$ & $\begin{array}{l}\text { CO: }+0.0824^{* *} \\
\text { nCo: }+0.0642^{* *} \\
\text { spo11:+0.0664** } \\
\text { dmc1: } \\
+0.0932^{* * *} \\
\text { mre11 }: \\
+0.0609^{* *} \\
\text { mre11 }:: 0.757^{* *}\end{array}$ \\
\hline
\end{tabular}

Spearman Rank Correlations of directed substitutions at four-fold degenerated sites (that to not change the non-optimal status) and of the proportion of AT$>\mathrm{GC}$ substitutions with gene length, expression, and various recombination measures, with and without controlling for an effect of gene position. Presented are also MR results of variables whose log-transformation did not grossly deviate from a normal distribution. ${ }^{*} \mathrm{P}<0.05$, ${ }^{* *} \mathrm{P}<0.01$, ${ }^{* * *} \mathrm{P}<0.001$, NS = not significant.

expression level (Table 5); this may be due to coupling of recombination and expression in yeast or indicate again a selective force favouring GC.

After control for gene position, the decrease with expression, and the opposing effects of recombination on rates of $\mathrm{GC}->\mathrm{AT}$ and $\mathrm{AT}->\mathrm{GC}$ remain (but the latter are not significant for the rate of AT->GC, Table 5). Interestingly, the general increase of substitution rates with gene length disappears. Also, the proportion of AT-> GC changes does not correlate with gene length anymore, indicating again the effect of gene position. Why the rate of AT->AT changes decreases with gene length after control of gene position is unclear (Table 5).

MR analysis of log-transformed variables confirms independent effects of gene length, recombination and expression for AT->GC and GC->AT changes; independent effects of gene length disappear after controlling for gene position (Table 5). Only little of the overall variation for AT->GC and GC->AT changes is explained by the variables (Table 5 ).

\section{Recombination measures}

The different recombination measures all tend to be conform in their general result; just for the substitution analysis, not all recombination measures support the 
finding. In general, dmc1 double-strand break (DSB) data tends to correlate strongest with GC-ending codons, followed by spo11 (spo) DSB and crossing-over (Co) events. But also non-crossing over events ( $\mathrm{nCo}$ ) and mre11 DSB data before and after meiosis and recombination (mre $11_{0}$ and $\mathrm{mre}_{1} 1_{6}$ respectively) confirms the finding. For the MR analysis, only dmc1 and mre $11_{0}$ were considered as their log-transformation deviated the least from the bell-shaped normal distribution.

\section{Discussion}

Separating translational selection from base composition indicates that in yeast frequency of GC-ending (optimal AND non-optimal) codons decreases with gene length and increases with recombination. This effect of base composition cannot be explained by variation in strength and efficiency of translational selection. GC-biased gene conversion appears the most likely explanation for the correlations with gene length and recombination. A decrease of GC-ending codons along genes is indicated and contributes to the decrease with gene length. Patterns of synonymous substitutions at four-fold degenerated sites support differences between $A T->G C$ and GC->AT substitutions related to recombination, as expected under GC-biased gene conversion. Selection on GC-ending codons, for instance due to selection mRNA secondary structures may also contribute.

In models of homologous recombination that relate to double-strand break (DSB) repair, mismatches in the formed heteroduplex may be repaired by gene conversion, i.e. the conversion of one DNA strand into another, and the formed Holliday junction can then either be resolved with or without crossing-over [51-54]. Gene-conversion is biased towards - GC in yeast as in several other organisms and has been suggested before to affect synonymous codon use [see for review [36]]. However in studies investigating the effect of gene conversion on codon use or on patterns of divergence and polymorphism effects of gene length and gene position have not been considered before. An effect of gene position and length may arise as gene conversion events are not randomly distributed across the genome; the number of gene conversion events should for example relate to the number of initiating DSBs and interestingly the number of DSBs already decreases with gene length in the yeast data assembled here $\left(-0.2590^{* * * *}\right)$. It is known that DSBs are often located in promoters with highest conversion numbers near the initiating DSBs [55-57]. Especially with short conversion tract lengths, the probability of gene conversion will hence decrease with distance from the DSB, i.e. from the promoter. If GCbiased, gene conversion could hence cause the negative correlation of GC-ending codons with gene position and thereby gene length. Gene conversion gradients, the decrease of gene conversion from one end of the gene to the other, have been observed in S. cerevisiae and other fungi [see [58] and references therein]. This decrease further seems often uni-directional in the 5'->3' direction, which may be due to various reasons including a gradient in heteroduplex formation or a gradient in the relative repair with gene conversion (as opposed to repair with restoration) $[59,60]$.

Three recent studies in yeast are interesting with respect to the results of this study and GC-biased gene conversion. Noor [61] looks at the correlation of intergenic and intronic substitution rates with recombination to test for mutagenic effects of recombination on substitution rates; the lack of an increase of substitution rates with recombination however suggests mutagenic effects of recombination do not affect the substitution rates in yeast very much. The decrease Noor [61] observes instead is conform with GC-biased gene conversion; however surprisingly, he finds no difference between GC->AT and AT->GC substitutions associated with DSBs. Weber and Hurst [62] find a decrease of nonsynonymous substitution rates with recombination, and interestingly not only with crossover but also with noncrossover events, which again is conform with GCbiased gene conversion. Referring to Noor's [61] lack of difference between GC->AT and AT->GC, they do not discuss GC-biased gene conversion further. Harrisson and Charlesworth [63] investigate the effect of GCbiased gene conversion in much detail, but do not consider the negative correlation between optimal codons and gene position and length. The potential contribution and importance of GC-biased gene conversion to observed patterns of substitutions for primates and humans have been highlighted much recently [see e.g. [64-67]] and in humans gene conversion tracts are short and steep [68]. It would be interesting whether an effect of gene position and length may be observed.

Besides a compositional bias in repair, such as GC-biased gene conversion, a negative correlation of GC-content at synonymous sites with gene length could also be due to a compositional bias in selection or mutation. Selection alternative to translational selection may differentiate among GC- and AT-ending codons, and its strength or efficiency could correlate with gene length and position. One selective target related to gene length and $\mathrm{GC}$-content is the stability of secondary structures. Thermodynamic stability of mRNA structures increases with gene length and GC-content as the absolute thermodynamic stability of a sequence will depend on the absolute number paired bases, and their strength of bonds, which is highest for pairs of $\mathrm{G}$ and $\mathrm{C}$. Laboratory studies suggest too stable secondary structures within the protein coding part interfere with 
translation [69], in which case selection should disfavour too stable structures. Especially in genes that are more stable through their length, lower level of GC may be beneficial and selected for. This could theoretically lead to the observed negative correlation of GC-ending codons with gene length. It may also explain a negative correlation of the GC-content with expression level (Table 2): first, selection on thermodynamic stability may vary with expression, and secondly, higher expressed genes will be shorter, and if the absolute stability would be under selection, their GC-content may be higher. Whether selection favours or dis-favours stability in protein coding regions however is a controversial issue [see e.g. [43-46]], for yeast, selection may indeed act against too stable structures [46]. However, even under selection against too stable secondary structures in coding mRNAs, it is not obvious why there should be a decrease of GC with gene position.

Variation in rate or bias of mutations may also contribute to the observed patterns, and mutations appears to be biased towards AT in yeast [70]. In this case however, polymorphism data should show the same patterns as divergence.

Note that in contrast to yeast, in E. coli, relative optimal codon use of all amino acids increases in frequency with gene length; this is independent of whether the optimal codon ends in AT- or GC- [12]. A possibly related difference between prokaryotes and eukaryotes is indicated in a separate line of studies: in prokaryotes GC-content increases with gene length [71,72], while in eukaryotes it mainly decreases [72]. It will be interesting to check other organisms for a decrease of GC-ending codons with gene length and gene position, and evaluate the effect of base composition - and GC-biased gene conversion - on synonymous (and optimal) codon use and sequence evolution.

GC-biased gene conversion may contribute to the negative correlation of (GC-ending) optimal codons with gene length described in various organisms, which so far has been explained only by variation in the strength or efficacy of translational selection. HillRobertson Interference has been suggested to cause the negative correlation between optimal codon use and gene length, and while Hill-Robertson Interference may contribute to several patterns of synonymous codon use [e.g. [16,23-29]], it cannot easily explain the here described compositional correlations for yeast that affect both optimal and non-optimal codons. Loewe and Charlesworth [27] included gene conversion in their model of intragenic background selection and highlight its contribution in breaking down linkage. It will be interesting to set up models that include also current knowledge on gene conversion bias towards GC, distribution of DSBs, e.g. the relation to promoters, the conversion lengths and dependencies on homology.

\section{Conclusion}

Separating translational selection from base composition indicates that in yeast frequencies of GC-ending (optimal AND non-optimal) codons decrease with gene length and position and increase with recombination. GC-biased gene conversion appears the most likely explanation. Substitution patterns support effects of GCbiased gene conversion. These results are of interest for our understanding of the process of gene conversion and its implications, but also for interpreting the negative correlation between optimal codon use and gene length observed in various organisms whose optimal codons tend to end with -GC.

\section{Methods \\ Data}

I used the data set kindly provided by Weber and Hurst [62]. This data includes (i) alignments of S. cerevisiae, S. mikitae and S. paradoxus, (ii) expression data [73], (iii) crossover and non-crossover recombination events [74], Spo11 double-strand break (DSB) data [56], Dmc1 DSB data [75], and Mre11 DSB data preceding meiosis and recombination and Mre11 DSB data after recombination, $\mathrm{mre}_{1} 1_{0}$ and $\mathrm{mre} 11_{6}$ respectively [76].

\section{Optimal Codons}

Optimal codons are defined as in [77] 12 optimal codons end with $\mathrm{G}$ or $\mathrm{C}$ (-GC), 12 with A or T (-AT), 17 non-optimal ones end with -GC, 18 with -AT. Throughout the paper, the terms "optimal" and "nonoptimal" will refer to translational selection alone. Codon identification is based on the $S$. cerevisiae sequence.

\section{Difference between optimal codons depending on whether they end with -AT or -GC}

To check whether the correlation between the relative frequency of optimal codons and gene length differs for $\mathrm{AT}$ - and GC-ending optimal codons, I compute $\mathrm{F}_{\mathrm{OPi}}$, the relative frequency of optimal codons $\left(\mathrm{F}_{\mathrm{OP}}\right)$ for each contributing amino acid (i) separately: $\mathrm{F}_{\mathrm{OP}}$, = number of respective optimal codon divided by the number of all codons for the respective amino acid. For amino acids with both - one AT- as well as one GC-ending optimal codon (Thr, Val, Ile, Ser), I compute the relative optimal codon frequencies of the two optimal codons separately. Serine for example has two optimal codons, TCT and TCC, and if I would count one TCT, two $\mathrm{TCC}$ and five non-optimal codons in a gene, $\mathrm{F}_{\mathrm{OP}} \mathrm{TCT}=$ $1 /(5+1)$ and $\mathrm{F}_{\mathrm{OP}} \mathrm{TCC}=2 /(5+2)$. I further group amino 
acids with AT - (Ala, Arg, Gly, Gln, Glu, Pro, Cys) and GC-ending (Leu, Lys, Phe, Tyr, His, Asp, Asn) optimal codons and compute the relative frequency of optimal codons across them.

\section{Effect of base composition independent of translational selection}

For amino acids with at least two optimal (Ile, Ser, Thr, Val) or two non-optimal codons (Ser, Thr, Val, Pro, Ala, Arg, Gly, Leu), one can further control for effects of translational selection by separately computing the relative frequencies of GC-ending optimal ( $\mathrm{F}_{\mathrm{GC}}$ optimal) and nonoptimal ( $\mathrm{F}_{\mathrm{GC}}$ non-optimal) codons. For example, if I would count 15 serine codons in a gene, 9 of which are optimal and three of the nine optimal codons end with -GC, then $\mathrm{F}_{\mathrm{GC}}$ optimal $=3 / 9$; if 2 of the remaining 6 non-optimal Serine codons end with $-\mathrm{GC}, \mathrm{F}_{\mathrm{GC}}$ non-optimal $=2 / 6$. Again, $\mathrm{I}$ also group the optimal or non-optimal codons of the respective amino acids and compute relative frequencies of GC-ending codons across them.

\section{Effect of gene position on relative codon frequencies}

Codon use may vary along genes, e.g. optimal or GCending codons may increase or decrease along the length of a gene $[29,40]$. Such an increase or decrease with gene position is of interest for itself, but also, as it can affect the correlation with gene length. To investigate the effect of gene position itself, I generate supersequences for codon position 50-200 across genes [see [29]]. To control for an effect of gene position, I take genes that are greater than 300 codons and only consider the level of bias in those codons up to that length [12]. I exclude the first 50 codons that may be under conflicting selection pressures $[29,76]$.

\section{Substitution rates and patterns}

To investigate whether the substitution patterns supports GC-biased gene conversion, I look at all non-optimal four-fold degenerated sites (Pro, Thr, Val, Ala, Gly, Leu, Ser, Arg) that are conserved in amino acid as across the three yeasts. To control for translational selection, I only look at sites that are conserved in their nonoptimal status across the three yeasts. I count sites with conserved codons, and sites with synonymous changes at the $3^{\text {rd }}$ codon position between $S$. cerevisiae and S. mikitae for which S. mikitae and S. paradoxus are conserved, and the change hence likely occurred in S. cerevisiae. I count substitution types (i) AT->GC, (ii) $\mathrm{GC}->\mathrm{AT}$, and (iii) AT->AT or (iv) GC->GC, and take their proportions relative to the respective codons that are conserved in S. cerevisiae, e.g. AT->GC/ATconserved. Also, I compare the rate of substitutions $\mathrm{AT}->\mathrm{GC}$ to all $\mathrm{AT}<->\mathrm{GC}$ substitutions.

\section{Statistics}

I use Spearman rank correlation analyses to investigate the correlation of relative codon frequencies or the substitution rate estimates with expression, recombination, gene length and gene position. I further performed multiple regression (MR) analysis. While the log-transformed variables do not seem to deviate grossly from normal distribution, normality could not be established for the variables using Kolmogorov-Smirnov-Lilliefors test. It is known however that with large sample size, minor deviations from normality can be statistically significant. For recombination estimates, only dmc1 and mre $11_{0}$ were used as they deviate the least from normality. In general, first order interaction terms did not increase the explainable variance significantly.

\section{Acknowledgements}

I am very grateful to Adam Eyre-Walker: for many helpful suggestions at various stages of the project and for pointing me to $F_{\mathrm{GC}}$ I I thank Adam EyreWalker, John Welch and the anonymous referees very much for helpful comments on the manuscript. I appreciate that I was partly supported by an Emmy-Noether grant to Joachim Hermisson.

\section{Author details}

'Ludwig-Maximilan Universität, Biocenter, Grosshadernerstr. 2, D-82152 Planegg-Martinsried, Germany. ${ }^{2}$ Centre for the Study of Evolution, School of Life Sciences, University of Sussex, Brighton BN1 9QG, UK. ${ }^{3}$ Current Address: Division of Genetics, Brigham and Women's Hospital, Harvard Medical School, 77, Louis Pasteur Avenue, NRB, Boston, MA, USA.

\section{Authors' contributions}

NS carried out the analyses, conceived of the study, and wrote the manuscript.

Received: 14 May 2010 Accepted: 11 April 2011 Published: 11 April 2011

\section{References}

1. Bulmer M: The selection-mutation-drift theory of synonymous codon usage. Genetics 1991, 129:897-907.

2. Akashi $\mathrm{H}$, Eyre-Walker A: Translational selection and molecular evolution. Curr Opinion Genet \& Dev 1998, 8:688-693.

3. Akashi H: Gene expression and molecular evolution. Curr Opin Genetics \& Dev 2001, 11:660-666.

4. Duret L: Evolution of synonymous codon usage in metazoans. Curr Opin Genet Dev 2002, 12:640-649.

5. Sorensen MA, Petersen S: Absolute in vivo translation rates of individual codons in Escherichia coli. The two glutamic acid codons GAA and GAG are translated with a threefold difference in rate. J Mol Biol 1991, 222:265-280.

6. Andersen SGE, Kurland CG: Codon preferences in free-living microorganisms. Microbiol Rev 1990, 54:198-210.

7. Parker J: Errors and alternatives in reading the universal genetic code. Microbiol Rev 1989, 53:273-298.

8. Carlini DB, Stephan W: In vivo introduction of unpreferred synonymous codons into the Drosophila Adh gene results in reduced levels of ADH protein. Genetics 2003, 163:239-243.

9. Eyre-Walker A: Synonymous codon bias is related to gene length in Escherichia coli: selection for translational accuracy? Mol Biol Evol 1996, 13:864-872.

10. Coghlan A, Wolfe KH: Relationship of codon bias to mRNA concentration and protein length in Saccharomyces cerevisiae. Yeast 2000, 16:1131-1145.

11. Moriyama EN, Powell JR: Gene length and codon usage bias in Drosophila melanogaster, Saccharomyces cerevisiae and Escherichia coli. Nucleic Acid Research 1998, 26(13):3188-3193. 
12. Stoletzki N, Eyre-Walker A: Synonymous Codon Usage in Escherichia coli: Selection for Translational Accuracy. Mol Biol Evol 2007, 24:374-381.

13. Akashi H: Synonymous Codon Usage in Drosophila melanogaster: Natural Selection and Translational Accuracy. Genetics 1994, 136:927-935.

14. Marais G, Duret L: Synonymous Codon Usage, Accuracy of Translation, and Gene Length in Caenorhabditis elegans. J Mol Evol 2001, 52:275-280.

15. Drummond DA, Wilke CO: Mistranslation-Induced Protein Misfolding as a Dominant Constraint on Coding-Sequence Evolution. Cell 2008, 134:2341-352

16. Comeron JM, Kreitman M, Aguade M: Natural selection on synonymous sites is correlated with gene length and recombination in Drosophila. Genetics 1999, 151:239-249.

17. Duret L, Mouchiroud D: Expression pattern and, surprisingly, gene length shape codon usage in Caenorhabditis, Drosophila, and Arabidopsis. Proc Natl Acad Sci USA 1999, 96:4482-4487.

18. Comeron JM: Selective and Mutational Patterns Associated With Gene Expression in Humans: Influence on Synonymous Composition and Intron Presence. Genetics 2004, 167:1293-1304.

19. Akashi H: Translational Selection and Yeast Proteome Evolution. Genetics 2003, 164:1291-1303.

20. Marais $G$, Mouchiroud D, Duret L: Neutral effect of recombination on base composition. Genet Res Camb 2003, 81:79-87.

21. Akashi H: Molecular Evolution Between Drosophila melanogaster and $D$. simulans: Reduced Codon Bias, Faster Rates of Amino Acid Substitution, and Larger Proteins in D. melanogaster. Genetics 1996, 144:1297-1307.

22. Hill WG, Robertson A: The effect of linkage on limits to artificial selection. Genet Res 1966, 8(3):269-94.

23. Betancourt A, Presgraves D: Linkage limits the power of natural selection in Drosophila. Proc Natl Acad Sci USA 2002, 99:13616-13620.

24. Comeron JM, Kreitman M: The correlation between intron length and recombination in Drosophila: dynamic equilibrium between mutational and selective forces. Genetics 2000, 156:1175-1190.

25. Comeron JM, Kreitman M: Population, evolutionary and genomic consequences of interference selection. Genetics 2002, 161:389-410.

26. Comeron JM, Guthrie TB: Intragenic Hill-Robertson Interference influences selection intensity on synonymous mutations in Drosophila. Mol Biol Evol 2005, 22:2519-2530.

27. Loewe L, Charlesworth B: Background selection in single genes may explain patterns of codon bias. Genetics 2007, 175:1381-1393.

28. McVean GAT, Charlesworth B: The effects of Hill-Robertson Interference between weakly selected mutations on patterns of molecular evolution and variation. Genetics 2000, 155:929-944

29. Qin H, Wu WB, Comeron JM, Kreitman M, Li WH: Intragenic spatial patterns of codon usage bias in prokaryotic and eukaryotic genomes. Genetics 2004, 168:2245-2260.

30. Kliman RM, Hey J: Reduced natural selection associated with low recombination in Drosophila melanogaster. Mol Biol Evol 1993, 10:1239-1258.

31. Hey J, Kliman RM: Interactions between natural selection, recombination and gene density in the genes of Drosophila. Genetics 2002, 160:595-608.

32. Kliman RM, Hey J: Hill-Robertson interference in Drosophila melanogaster: reply to Marais, Mouchiroud and Duret. Genet Res Camb 2003, 81:89-90.

33. Eyre-Walker A: Recombination and mammalian genome evolution. Proc Roy Soc London Series B 1993, 252:237-243.

34. Birdsell JA: Integrating genomics, bioinformatics, and classical genetics to study the effects of recombination on genome evolution. Mol Biol Evol 2002, 19:1181-1197.

35. Galtier N, Bazin E, Bierne N: GC-biased segregation of non-coding polymorphisms in Drosophila. Genetics 2006, 172:221-228.

36. Marais G: Biased gene conversion: implications for genome and sex evolution. TRENDS in Genetics 2003, 19(6):330-338.

37. Marais $G$, Mouchiroud $D$, Duret $L$ : Does recombination improve selection on codon usage? Lessons from a nematode and fly complete genomes. Proc Natl Acad Sci USA 2001, 10:5688-5692, 98.

38. Ikemura T: Review Codon Usage and tRNA Content in Unicellular and Multicellular Organisms. Mol Biol Evol 1985, 2:13-34.

39. Percudani R, Pavesi A, Ottonello S: Transfer RNA gene redundancy and translational selection in Saccharomyces cerevisiae. J Mol Biol 1997, 268:322-330.

40. Plotkin JB, Fraser HB: Assessing the Determinants of Evolutionary Rates in the Presence of Noise. Mol Biol Evol 2007, 24:113-1121.
41. Drummond DA, Raval A, Wilke COA: Single Determinant Dominates the Rate of Yeast Protein Evolution. Mol Biol Evol 2006, 23:327-337.

42. Nicolas A: Relationship between transcription and initiation of meiotic recombination: toward chromatin accessibility. Proc Natl Acad Sci USA $1998,95: 87-89$

43. Chamary JV, Hurst LD: Evidence for selection on synonymous mutations affecting stability of mRNA secondary structure in mammals. Genome Biol 2005, 6:R75

44. Seffens W, Digby D: mRNAs have greater negative folding free energies than shuffled or codon choice randomized sequences. Nucleic Acids Res 1999, 27:1578-1584.

45. Katz L, Burge CB: Widespread selection for Local RNA secondary Structure in Coding Regions of Bacterial Genes. Genome Research 2003, 13:2042-2051.

46. Stoletzki N: Conflicting selection pressures on synonymous codon use in yeast indicate selection on mRNA secondary structures. BMC Evolutionary Biology 2008, 8:224

47. Kliman RM, Eyre-Walker A: Patterns of base composition within the genes of Drosophila melanogaster. J Mol Evol 1998, 46:534-541.

48. Eyre-Walker A, Bulmer M: Reduced synonymous substitution rate at the start of enterobacterial genes. Nucleic Acid Research 1993, 21(19):4599-4603.

49. Sueoka N: On the Genetic Basis of Variation and Heterogeneity of DNA Base Composition. Proc Natl Acad Sci USA 1962, 48:582-591.

50. Lynch M, Sung W, Morris K, Coffey N, Landry CR, Dopman EB, Dickinson WJ, Okamoto K, Kulkarni S, Hartl DL, Thomas WK: A genome-wide view of the spectrum of spontaneous mutations in yeast. Proc Natl Acad Sci USA 2008, 105:9272-9277

51. Szostak JW, Orr-Weaver TL, Rothstein RJ, Stahl FW: The Double-StrandBreak Repair Model for Recombination. Cell 1983, 33:25-35.

52. Smith KN, Nicolas A: Recombination at work for meiosis. Curr Opin Genet Dev 1998, 8:200-211.

53. Inbar O, Liefshitz B, Bitan G, Kupiec M: The relationship between homology length and crossing over during the repair of a broken chromosome. J Biol Chem 2000, 275(40):30833-30838.

54. Paques F, Haber JE: Multiple pathways of recombination induced by double-strand breaks in Saccharomyces cerevisiae. Microbiology and Molecular Biology Reviews 1999, 63(2):349-404.

55. Baudat F, Nicolas A: Clustering of meiotic double-strand breaks on yeast chromosome III. Proc Natl Acad Sci USA 1997, 94:5213-5218.

56. Gerton JL, DeRisi J, Shroff R, Lichten M, Brown PO, Petes TD: Global mapping of meiotic recombination hotspots and coldspots in the yeast. Saccharomyces cerevisiae

57. de Massy B: Distribution of meiotic recombination sites. TRENDS in Genetics 2003, 18(9):514-522.

58. Borts RH, Chambers SR, Abdulah MFF: The many faces of mismatch repair in meiosis. Mutation Research 2000, 451:129-150

59. Detloff P, White MA, Petes TD: Analysis of a Gene Conversion Gradient at the HIS4 Locus in Saccharomyces cerevisiae. Genetics 1992, 132:113-123.

60. Merker JD, Dominska M, TD Petes TD: Patterns of Heteroduplex Formation Associated With the Initiation of Meiotic Recombination in the Yeast Saccharomyces cerevisiae. Genetics 2003, 165:47-63.

61. Noor M: Mutagenesis from Meiotic Recombination Is Not a Primary Driver of Sequence Divergence between Saccharomyces Species. Mol Biol Evol 2008, 25:2439-2444.

62. Weber CC, Hurst LD: Protein Rates of Evolution Are Predicted by DoubleStrand Break Events, Independent of Crossing-over Rates. Gen Biol Evol 2009, 1:340-349

63. Harrison RJ, Charlesworth B: Biased Gene Conversion Affects Patterns of Codon Usage and Amino Acid Usage in the Saccharomyces sensu stricto Group of Yeasts. Mol Biol Evol 2011, 28:117-129.

64. Galtier N, Duret L: Adaptation or biased gene conversion? Extending the null hypothesis of molecular evolution. Trends in Genetics 2007, 23(6):273-277.

65. Galtier N, Duret L, Glemin S, Ranwez V: GC-biased gene conversion promotes the fixation of deleterious amino acid changes in primates. Trends in Genetics 2009, 25(1):1-5.

66. Berglund J, Pollard KS, Webster MT: Hotspots of Biased Nucleotide Substitutions in Human Genes. PLOS Biology 2009, 7(1):0045-0062.

67. Duret $L$, Arndt $P$ : The Impact of Recombination on Nucleotide Substitutions in the Human Genome. PLOS Genetics 2008, 5(5):e1000071. 
68. Jeffreys AJ, May CA: Intense and highly localized gene conversion activity in human meiotic crossover hotspots. Nature Genetics 2004, 36(2):151-156.

69. Doma MK, Parker R: Endonucleotic cleavage of eukaryotic mRNAs with stalls in translation elongation. Nature 2006, 440:561-564.

70. Lynch M, Sung W, Morris K, Coffey N, Landry CR, Dopman EB, Dickinson WJ, Okamoto K, Kulkarni S, Hartl DL, Thomas WK: A genome-wide view of the spectrum of spontaneous mutations in yeast. Proc Natl Acad Sci USA 2008, 105:9272-9277

71. Oliver JL, Marin A: A relationship between GC-content and coding sequence length. J Mol Evol 1996, 43:216-223.

72. Xia X, Xie Z, Li WH: Effects of GC content and mutational pressure on the lengths of exons and coding sequences. J Mol Evol 2003, 56:362-370.

73. Holstege FC, Jennings EG, Wyrick JJ, Lee TI, Hengartner CJ, Green MR, Golub TR, Lander ES, Young RA: Dissecting the regulatory cicuity of a eukaryotic genome. Cell 1998, 95:717-728.

74. Mancera E, Bourgon R, Brozzi A, Huber W, Steinmetz LM: High-resolution mapping of meiotic crossovers and non-crossovers in yeast. Nature 2008, 454:479-485, Proc Natl Acad Sci USA 2000, 97(21): 11383-11390.

75. Buhler C, Borde V, Lichten M: Mapping Meiotic Single-Strand DNA Reveals a New Landscape of DNA Double-Strand Breaks in Saccharomyces cerevisiae. PLoS Biol 2007, 5:e324

76. Borde $\mathrm{V}$, Lin W, Novikov $E$, Petrini JH, Lichten M, Nicolas A: Association of Mre11p with Double-Strand Break Sites during Yeast Meiosis. Mol Cell 2004, 13:3389-401.

77. Kliman RM, Irving N, Santiago M: Selection conflicts, gene expression, and codon usage trends in yeast. J Mol Biol 2003, 57(1):98-109.

doi:10.1186/1471-2148-11-93

Cite this article as: Stoletzki: The surprising negative correlation of gene length and optimal codon use - disentangling translational selection from GC-biased gene conversion in yeast. BMC Evolutionary Biology 2011 11:93.

\section{Submit your next manuscript to BioMed Central} and take full advantage of:

- Convenient online submission

- Thorough peer review

- No space constraints or color figure charges

- Immediate publication on acceptance

- Inclusion in PubMed, CAS, Scopus and Google Scholar

- Research which is freely available for redistribution

Submit your manuscript at www.biomedcentral.com/submit 